Penelitian Bidang Komputer Sains dan Pendidikan Informatika V3.i2(121-124)

\title{
"SIWANPEKERJA" : THE INFORMATION SYSTEM OF ENTREPRENEURSHIP, THE TRADITIONAL REGIONAL FOOD SPECIALTIES (KERUPUK, RENDANG AND SANJAI) IN PAYAKUMBUH.
}

\author{
Thomson Mary \\ Pendidikan Informatika, STKIP PGRI Sumatera Barat \\ email: thomsonmary1980@gmail.com
}

\author{
Submitted: 16-03-2017, Reviewed: 17 -03- 2017, Accepted 18-03-2017 \\ http://dx.doi.org/10.22202/jei.2017.v3i2.1620
}

\begin{abstract}
The paper is based on research results on Small and Medium Enterprises in Indonesia where its scope in Payakumbuh city of West Sumatra Province. A survey conducted in 2014 until early 2015 in some units of small and medium enterprises in the city Pakumbuh include traditional food business; crackers, Sanjai and rendang. The business is still run by the traditional and still do not have an integrated information system that is adequate and do not have a database that is useless for mapping potential areas of culinary tourism, business development to the continued efforts of government assistance. The system will be built to collect all data about them in the Enterprise Information System Crackers, Sanjai and Rendang (Siwanpekerja). Data were analyzed with a system of SDLC (System Development Life cicle) that encapsulates the actors involved in this project. The Actors are; User system from a cottage industry entrepreneurs, Sellers, Buyers and Governments are summarized in an integrated information system that Payakumbuh has the most complete database in the development of culinary tourism in Indonesia. The results obtained in this study is in the form of an information system "Siwanpekerja" to accommodate the actors to belong in a database so Payakumbuh government and the Small and Medium businesses benefit greatl. Conclusion of "Siwankapus" has certain advantages, namely; facilitate the provision of assistance from the government, facilitate marketing, and entrepreneurial development for the future
\end{abstract}

Keywords : Information System, Traditional Food, Culinary Tourism,

\section{PENDAHULUAN}

Usaha Kecil dan Menengah (UKM) merupakan usaha tradisional yang dijalankan oleh masyarakat secara tradisional baik itu pengolahan, pemasaran dan pengembangannya. banyaknya usaha kecil dan menengah yang tidak diketahui pemetaannya di suatu Permasalahan yang ditemui saat ini yaitu ; wilayah, banyaknya home industry yang belum mendapatkan bantuan dari pemerintah, serta pemasaran yang masih bersifat lokal.

Perdagangan bebas Asean atau yang dikenal sebagai Masyarakat Ekonomi Asean (MEA) 2015 sedang berjalan. Semua sektor usaha dan bisnis ikut meramaikannya tanpa terkecuali sektor usaha mikro, kecil dan menengah (UMKM). UMKM menjadi pusat perhatian sampai saat ini karena pertumbuhannya yang sangat signifikan di setiap tahunnya dan peluang adanya peningkatan pendapatan bagi pelaku UMKM[1]

Pengembangan Industri Kecil dan Menengah dijadikan Kementerian Perindustrian sebagai sektor pendorong guna mencapai Visi Pembangunan Industri Nasional Jangka Panjang, yaitu membawa Indonesia menjadi Negara Industri Tangguh Dunia pada tahun 2025 [2].

Salah satu misi yang diemban untuk mencapai visi tersebut adalah penggunaan 
Penelitian Bidang Komputer Sains dan Pendidikan Informatika V3.i2(121-124)

teknologi yang dijadikan alat bantu utama dalam pengembangan produk dan penciptaan pasar [2]

Permasalahan yang muncul adalah UKM tersebut belum terdata dengan sistem informasi terpadu oleh pemerintah dalam hal ini Departemen Perindustrian, Pariwisata dan Pemerintah Daerah serta Departemen Kesehatan yang menyebabkan bantuan, akomodasi serta pengembangan wilayah yang berpotensi sebagai wisata menjadi belum terlaksana dengan maksimal.

Permasalahan lainnya yang terjadi yaitu kurangnya cakupan pasar regional maupun internasional, luas cakupan pemasaran saat ini sebagian besar masih bersifat lokal dimana pamasaran hanya di warung, outletoutlet dan toko-toko disekitar home industry sehingga jika konsumen menginginkan produk makanan tradisional tersebut, konsumen harus datang ke lokasi untuk mencari dan memilih produk walaupun dalam kunjungan pariwisata.

Penggunaan internet yang semakin tinggi diharapkan dapat memberikan manfaat dalam dunia bisnis yang makin kompetitif (Siregar, 2010; Zaky dan Wiharjanto, 2012; Tajuddin, 2011). Berdasarkan pemikiran tersebut maka, sistem informasi pemasaran berbasis online sangat diperlukan UMKM. Para pelaku UMKM tidak dapat menghindar lagi. Sistem informasi ini diharapkan dapat menciptakan keunggulan kompetitif sektor UMKM secara terintegrasi.[1]

Melalui sistem informasi pemasaran yang terintegrasi secara online diharapkan paket 4P (product, place, promotion, price) dan Bauran Terintegrasi dapat menghasilkan informasi yang tepat dan akurat guna pengambilan keputusan para pelaku UMKM sehingga keberlangsungan/sustainability UMKM tetap berjalan (Nowduri, 2014 dan Suardana, 2015)[1]

\section{METODE PENELITIAN}

Pembangunan dan pengembangan suatu sistem informasi adalah sebuah cara untuk memudahkan sebuah lembaga atau organisasi dalam memelihara dan menjamin sebuah keteraturan dalam pengorganisasian data dan informasi, oleh karena itu sebuah pembangunan dan pengembangan suatu sistem informasi membutuhkan sebuah perencanaan pengembangan yang tepat guna dan dapat bertahan lama serta mudah dikembangkan di kemudian hari.[2]

Adapun tujuan penelitian ini adalah untuk mengembangkan pariwisata khususnya kuliner di Payakumbuh dengan menciptakan sistem informasi terpadu yang dalam penelitian ini diberikan dalam bentuk Pemodelan Sistem Informasi yang mengakomodasikan ; pemesanan produk makanan tradisional, pembuatan basis data dan pemetaan wilayah potensial dalam pariwisata kuliner daerah serta untuk pengembangan wisata pada umumnya dan wisata kuliner khususnya di kota Payakumbuh.

SDLC merupakan suatu urutan dari beberapa proses secara bertahap didalam merancang dan mengembangkan sistem yang dikenal juga dengan nama Information System Development atau juga Application Development.[3]

Penelitian dikembangkan dengan pemodelan SDLC (System Development Life Cicle) sehingga mampu mengakomodasikan seluruh user atau pengguna dalam sistem tersebut. Pada Sistem SDLC pengguna yang berperan pada sistem ini adalah pemerintah dalam hal ini Departemen Perindustrian dan Pariwisata, home Industry dan seller. Metode SDLC dijelaskan dengan tampilan seperti berikut ini : 
Penelitian Bidang Komputer Sains dan Pendidikan Informatika V3.i2(121-124)

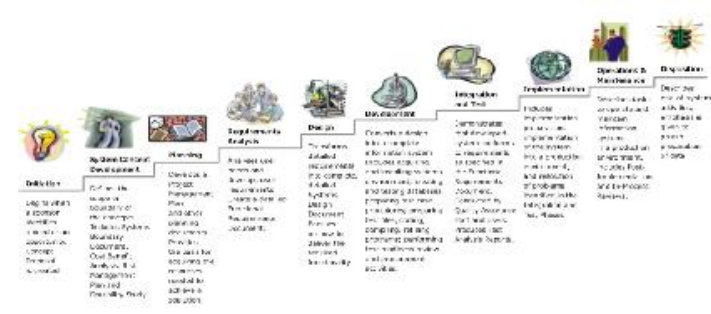

Gambar 1. Metode Kerja dengan SDLC

Pada Gambar 1 dijelaskan pemodelan sistem dengan SDLC dimana dilakukan secara bertahap dan kontinyu mulai ide dimunculkan (Insiasi), Planning, Design,hingga Implementation. Tahaptahapan tersebut dilakukan sedemikian rupa sehingga menghasilkan pemodelan Sistem Informasi yang dinamakan dengan "Siwanpekerja"

Dari kerja SDLC diturunkan pemodelan Sistem Informasi Siwanpekerja (Sistem Informasi Pemesanan Kerupuk dan Sanjai)

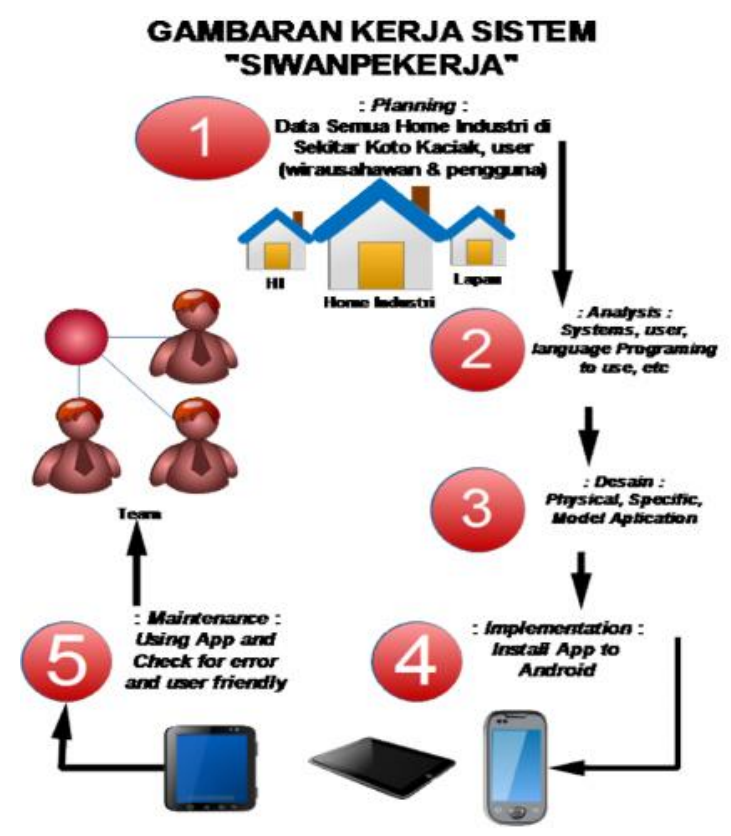

Gambar 2.Pemodelan Kerja Sistem “Siwanpekerja" pada Tiap Tahap SDLC

\section{HASIL DAN PEMBAHASAN}

Hasil penelitian pemodelan Sistem Informasi Penjualan Kerupuk dan Sanjai pada daerah Payakumbuh adalah sebagai berikut

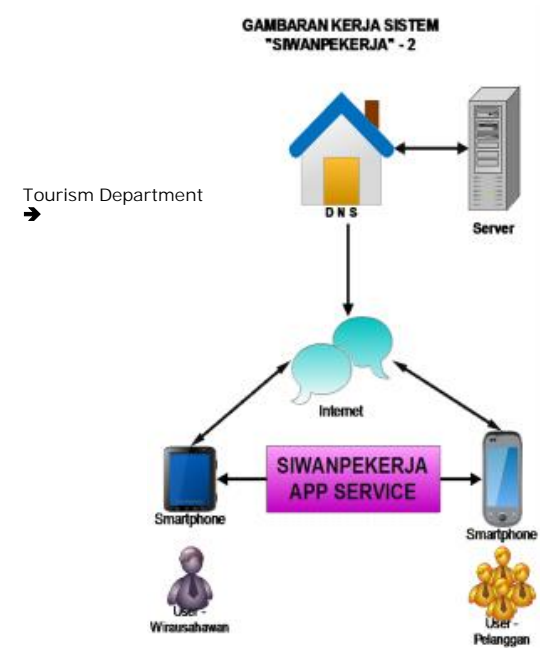

\section{Gambar 3.Pemodelan Kerja Sistem "Siwanpekerja"}

Server (System Management Centre) digunakan sebagai basis data untuk UKM dan dibawah kontrol departemen yang terkait sehingga memudahkan tindak lanjut pendataan untuk berbagai kepentingan

Hasil akhir diinterpretasikan sebagai gambar berikut

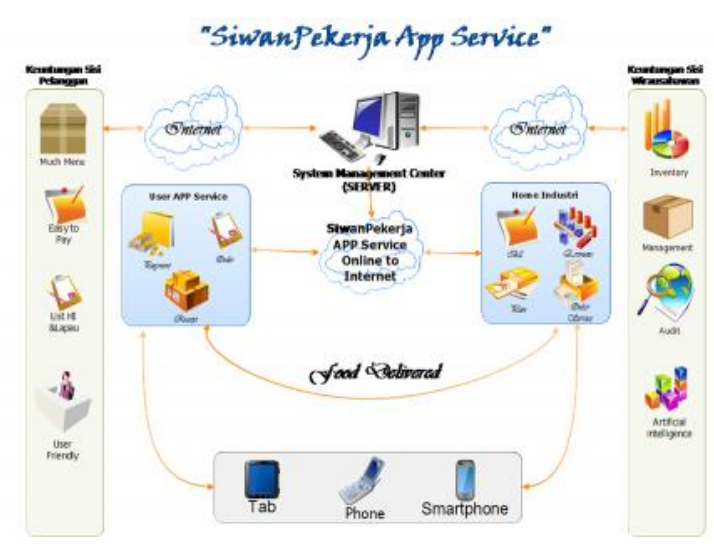

Gambar 4.Pemodelan Kerja Sistem "Siwanpekerja" dengan Aplikasi

\section{SIMPULAN}

Dengan adanya basis data, UKM akan terdata untuk memudahkan pemerintah mempetakan daerah penghasil produksi serta penyuluhan dan pemberian bantuan lainnya dari program-program pemerintah. 
Penelitian Bidang Komputer Sains dan Pendidikan Informatika V3.i2(121-124)

Siwanpekerja App Service merupakan aplikasi yang digunakan untuk transaksi jual beli produk UKM, informasi daerah wisata, serta basis data terintegrasi dengan Departemen Pariwisata dan Perindustrian untuk bantuan bagi UKM dalam mengembangkan usahanya.

\section{UCAPAN TERIMAKASIH}

Penulis mengucapkan terimakasih sebesar-besarnya kepada pemerintahan Nagari Jorong Koto Talago, pemerintah Kabupaten 50 Kota, Departemen Pariwisata dan Peindustrian atas kerjasamanya dalam pemberian informasi yang sangat berguna dalam penelitian ini.

\section{DAFTAR PUSTAKA}
A. A. G. Satia and I. Millati, "DESAIN MARKETING INFORMATION SYSTEMS PADA

USAHA MIKRO KECIL DAN MENENGAH ( UMKM ) DI," pp. 863-878.

[2] J. T. Industri, U. Pasundan, J. T. Pangan, U. Pasundan, J. T. Informatika, and U. Pasundan, "PEMBANGUNAN SISTEM INFORMASI BERBASIS WEB UNTUK MONITORING DAN EVALUASI SENTRA INDUSTRI KECIL DAN MENENGAH DI JAWA BARAT Rizki Wahyuniardi 1 , Leni Herliani Afrianti 2 , Sidik Nurjaman 1 dan Wanda Gusdya 3," vol. 4, no. 1, pp. 9-19, 2016.

[3] I. J. Dewanto, "Planning Planning Analysis Analysis Detailed Detailed System System Design Design Implementation Implementation Maintenance Maintenance," Syst. Dev. Life Cycle Dengan Beberapa Pendekatan, vol. 2, no. 1, 2004. 